\title{
Quando um biólogo é inundado por outras biologias, outras educações ${ }^{1}$
}

\author{
When a biologist is flooded with other biologies, other educations
}

Cuando un biólogo está financiado por otras biologías, otras educaciones

Carlos Augusto Silva e Silva - Instituto Federal de Rondônia | Departamento de Apoio ao Ensino | Jiparaná | RO | Brasil. Universidade Federal de Rondônia | Doutorando em Educação Escolar | Porto Velho | RO | Brasil. E-mail: carlosaugusto.s02@gmail.com

Maria dos Remédios de Brito - Universidade Federal do Pará | Instituto de Educação Matemática e Científica | Belém |PA | Brasil. E-mail: mrdbrito@hotmail.com | Dorci

Resumo: O texto partilha dos encontros vitais que mobilizaram, no corpo de um biólogo-artista, exercícios fabulatórios de experimentação - com a imagem, a escrita, a memória, as águas de um igarapé, a terra, as vidas que atravessaram moradores atingidos por uma barragem - aglutinados pelas seguintes questões: como um biólogo pode experimentar a biologia, a arte, a natureza para além do já posto? Como a arte e a biologia se cruzam com/na natureza e que educações se compõem nesses vazamentos? O texto vem com o desejo de instaurar um caos problemático nas concepções demasiadamente rígidas que enredam as biologias e seus atravessamentos na/com educação, tomando como inspiração conceitual a filosofia de Gilles Deleuze e Félix Guattari.

Palavras-chave: Biologia. Imagem. Deleuze.

Abstract: In this text we share the vital encounters that mobilized fable-like exercises of experimentation in the body of a biologist-artist. Exercises with images, writing, memory, waters of a stream, land, lives that crossed residents affected by a dam. Exercises that were joined by the following questions: how can a biologist experience biology, art, nature beyond what has already been said? How do art and biology intersect with / in nature and what educations are composed in these leakages? This text comes with the desire to originate a problematic chaos in the overly rigid conceptions that intertwine biologies and their crossings in / with education, taking as a conceptual inspiration the philosophy of Gilles Deleuze and Félix Guattari.

Keywords: Biology. Image. Deleuze.

\footnotetext{
${ }^{1} \mathrm{O}$ presente ensaio é fruto de uma dissertação de mestrado produzida junto ao Programa de Pós-Graduação em Educação em Ciências e Matemática da Universidade Federal do Pará (IEMCI-UFPA), defendida no ano de 2018 com o título "Experimentações art(e)biologia na/om a natureza", sendo financiada pela Coordenação de Aperfeiçoamento de Pessoal de Nível Superior CAPES. O ensaio fotográfico que compõe o texto foi publicado de maneira reduzida numa revista de divulgação científica denominada Revista Coletiva em 2018.
}

- Recebido em 21 de novembro de $2019 \cdot$ Aprovado em 18 de junho de 2020 • e-ISSN: 2177-5796

DOI: http://dx.doi.org/10.22483/2177-5796.2020v22n2p355-374

Copyright @ 2019. Conteúdo de acesso aberto, distribuído sob os termos da Licença Internaonal da CreativeCommons - CC BY-NC-SA Atribuição Não Comercial (https://br.creativecommons.org/licencas/) - Permite distribuição e reprodução, desde que atribuam os devido créditos à publicação, ao autor(es) e que licenciem as novas criações sob termos idênticos. 
SILVA, Carlos Augusto Silva e; BRITO, Maria dos Remédios de. Quando um biólogo é inundado por outras biologias, outras educações.

Resumen: El texto comparte los encuentros vitales que movilizaron, en el cuerpo de un biólogo-artista, fabulosos ejercicios de experimentación, con la imagen, la escritura, la memoria, las aguas de un arroyo, la tierra, las vidas que cruzaron los residentes afectados por una presa - aglutinada por las siguientes preguntas: ¿cómo puede un biólogo experimentar la biología, el arte, la naturaleza más allá de lo ya puesto? ¿Cómo se cruzan el arte y la biología con / en la naturaleza y qué educación componen estas filtraciones? El texto viene con el deseo de crear un caos problemático en las concepciones demasiado rígidas que enredan las biologías y sus cruces en / con la educación, tomando como inspiración conceptual la filosofía de Gilles Deleuze y Félix Guattari.

Palabras clave: Biología. Imagen. Deleuze. 
SILVA, Carlos Augusto Silva e; BRITO, Maria dos Remédios de. Quando um biólogo é inundado por outras biologias, outras educações.

\section{Um biólogo e seus encontros}

Artista-biólogo ou biólogo-artista? Essa pergunta se deslizou por entre os corredores de uma faculdade, no período em que um estudante cursava Ciências Biológicas e dividia seu tempo com processos artísticos, em especial a dança. Uma pergunta que buscava afirmar uma forma de viver e estar no mundo: abandonar/escolher a dança ou abandonar/escolher a biologia?

Eram perguntas que povoavam sua mente que tencionava a seguir um padrão, uma escolha, uma categoria para poder, de fato, inserir-se ou ser inserido na vida social mercantilista. Até que um dia, o biólogo decidiu experimentar o cruzamento de ambos: escutem-me amigos, professores, familiares. Escutem-me queridas bio-logias. Escutem-me por não conseguir escolher, já não quero mais. Escutem-me, não quero ser o mesmo. Escutem-me, se ainda não sou o mesmo. Escuto-me, por não ser mais quem sou. Como me tornei? Apenas me torno!

Como um biólogo poderia pensar em outras possibilidades de experimentar a ciência, a biologia, a arte, a natureza para além do já posto? Como a arte e a biologia se cruzam com/na natureza e que educações se compõe nesses vazamentos?

Deleuze e Guattari (2013) fazem pensar que não somos apenas habitantes do mundo, mas, sobretudo, transformamo-nos com ele. São transformações que cortaram o biólogo, que, até então, era incentivado apenas a ser um biólogo, mesmo com o seu curso sendo voltado para a formação de professores, era nítida a prevalência das biológicas em detrimento das pedagógicas, mas como já mencionado, transformamo-nos com o mundo, e o biólogo, que adorava dançar, e assim fez, mudou, ou melhor, dançou. Dançou por entre educação em ciências, formação de professores, hidrelétricas, igarapés, rios, açaizais e baixões, sem saber aonde iria parar e se iria parar.

Tais lugares, mencionados pelo biólogo no parágrafo anterior, mobilizaram o seu pensamento e fizeram pensar sobre as águas de um igarapé. O que ficou após os moradores serem removidos de suas casas por conta da instalação de um Complexo Hidrelétrico ${ }^{2}$ ? Uma imagem, uma lembrança, uma dança em movimento; águas que movimentaram corpos nutridos por elas, propõem-se movimentar.

\footnotetext{
2 Trata-se do complexo hidrelétrico de Belo Monte, um empreendimento energético, de iniciativa do Governo Federal, construído às margens do Rio Xingu, em especial no Município de Vitória do Xingu, afetando diretamente pelo menos nove municípios da região.
} 
SILVA, Carlos Augusto Silva e; BRITO, Maria dos Remédios de. Quando um biólogo é inundado por outras biologias, outras educações.

São disparadores para além do flash da câmera: memórias, lembranças, movimentos, envolvimentos, mar-manto, tecidos se movimentando sendo águas, rio. O rio ou igarapé que ali um dia se fez hoje se refaz, porém de outra forma, diferente. Como? Dançando. O igarapé Altamira, mesmo sujo, era lugar de habitação de diversos moradores, mas hoje o que ele é? O que pode se tornar? Vazio... Vazio... Vazio... Biólogos estudaram e fizeram testes de qualidade da água, análises sociais com os moradores e "revitalização" do ambiente, contudo o que outros biólogos podem propor nesse mesmo local que difere? É nesse sentido que o biólogo decide fabular outras experimentações, outros testes. Criação de novas memórias, novas formas de habitar o lugar desabitado. Ali, nas margens sujas é onde tudo começa: igarapé-rio-mar-oceano. É o ciclo descíclico.

O esforço teórico deste texto perpassou por inspirações da filosofia de Gilles Deleuze e Félix Guattari, que como bem nos diz Deleuze no seu livro Diferença e Repetição (2006, p. 237): "Não há um método para encontrar tesouros", portanto não se buscou por um único trajeto, ou um único método, mas a criação de uma cartografia, para talvez encontrar alguns tesouros, ou como diz Ramos e Brito (2018) outras visualidades para biologia e o seu ensino, novas maneiras de se entregar com/nos mundos ao redor de nós. Neste contexto, a cartografia é um plano de experiência, não se delimitando a um método (MASNY, 2013; BRITO; CHAVES, 2017), pois, antes de tudo, é um modo de vida. O rizoma ${ }^{3}$ é a porta de acesso.

Corazza e Silva (2003, p. 69) dizem que a cartografia serve "para saber o que pode um corpo" e lançam mão da seguinte problematização: “quais são os afectos de um corpo?”. Para, além disso, o pensamento deste texto se esquadrinha no seguinte questionamento: quais são os afectos de um biólogo que decide fabular outras biologias?

O enfoque neste ensaio não é diretamente no Biólogo em si, mas, principalmente, nos processos produzidos por ele que buscava por outras biologias, coletando não mais amostras inorgânicas, mas afectos, lembranças, transformando tudo isso numa art(e)biologia. Sem dizer o que essa biologia é, mas o que ela produziu.

\footnotetext{
${ }^{3}$ Rizoma trata-se de um conceito de Deleuze e Guattari esboçado com maior cuidado na obra Mil Platôs v.1, o qual os autores o caracterizam sendo heterogêneo e múltiplo. Nele não existe um centro, início ou fim, pode ser fissurado em qualquer lugar, conjugando sempre o "e...e...e...". Traz-se este conceito para acionar o leitor sobre possíveis entradas no texto, e uma leitura que pode se dar a partir de qualquer uma delas, trazendo outras narrativas não lineares que o leitor pode inventar.
} 
SILVA, Carlos Augusto Silva e; BRITO, Maria dos Remédios de. Quando um biólogo é inundado por outras biologias, outras educações.

Destarte, primeiramente, foi realizada uma conversa com os moradores dos bairros Açaizal e Tufi, os quais tinham contato direto com o igarapé Altamira. Após, tomada as informações, foi adquirido com os moradores fotos do local antes da instalação do Complexo Hidrelétrico de Belo Monte, ou seja, período em que os habitantes ainda moravam na localidade, com o intuito de realizar experimentações com estas fotografias do local antes do barramento e alguns objetos nas margens e no próprio igarapé.

Além disso, foi realizada uma instalação numa árvore no parque igarapé Altamira e que, de acordo com a biologia oficial, estaria morta. Trata-se de várias árvores que ali compunham o cenário, que não aguentaram ver seus vizinhos amigos serem arrancados, mesmo com biólogos, engenheiros ambientais e florestais lhe dando todo o suporte científico, não era isso que elas queriam.

As imagens, objetos, narrativas e escritas se misturam e exercitam uma fabulação ${ }^{4}$. Diante disso, vale ressaltar que não houve um aprofundamento explicativo neste ensaio, de maneira proposital, pois "a gente não gosta de explicar as imagens porque explicar afasta as falas da imaginação", é o que dizia Manoel de Barros (2015, p. 12).

As imagens podem ser pensadas como anamorfoses impossíveis, no sentido das sensações e devires causados pelos perceptos e afectos, não em um sentido representativo, porém, em movimentações que borram as formas. Imagens que não encerram o pensamento pensado, assim, abrem-se para novas possibilidades, rompendo com o regime da representação, regime este que lança mão da identidade em detrimento da diferença. Imagens associadas diretamente aos encontros e afetos, sendo que o segundo se dá pela contingência, através de múltiplos encontros não ordenados, "o afeto é a variação contínua da potência de agir de alguém" (MACHADO, 2009, p. 69).

Com Rancière o contato, a troca e a alteridade se embaraçam e compõem as imagens, não de maneira simples, entretanto, imagens que são as próprias performances, "não se remetem a nada além delas mesmas. Isso não quer dizer que elas sejam, como se falam comumente, intransitivas" (RANCIÈRE, 2012, p. 11). A intenção não foi interpretar, mas, quem sabe,

\footnotetext{
${ }^{4}$ Deleuze empresta a ideia bergsoniana de fabulação e estreita arte e política, para que assim possam ser inventadas linhas de fuga, modos outros de existências e de experimentações vitais (No caso deste estudo, experimentações art(e)biologia com a natureza). Na fabulação sucumbem-se as verdades universais, e não se tem um início e um fim, ou seja, a linearidade é rompida, instaurando devires, entretanto não se trata de uma solução, porém, de conectar-se às outras potências e forças de criação.
} 
SILVA, Carlos Augusto Silva e; BRITO, Maria dos Remédios de. Quando um biólogo é inundado por outras biologias, outras educações.

perceber acontecimentos irrepresentáveis. Foram imagens trazidas como experimentações, e não apenas como registro pictográfico que atarracam o sentido normal das ideias e das figuras. Jamais querer explicá-las. Cada imagem, cada gesto é uma possibilidade de entrada para um mundo sem formas rígidas dos pensamentos sem seguir modelos estabelecidos, é um pensar flexível.

As imagens penetram vidas e, também, podem impor sentidos, condutas que ao mesmo tempo estão presas numa malha mercadológica e comunicativa, são palavras articuladas que, a partir da linguagem, tentam dizer o que é a imagem; imagens como diz Pelbart, (2014, p. 253) "domesticadas à linguagem, imagens subordinadas à comunicação, imagens tomadas num sistema de troca ou da mercadoria [...]. À imagem repleta de intenções, de cultura”. Nesse sentido, penso naquelas imagens que viajam em direção ao mar, não as que permaneçam nele. São imagens vazias, não no sentido da desvalorização, mas, ainda, imagens que promovem acontecimentos, os quais, a partir dos encontros, fabricaram novas intensidades que existem na medida em que fazem existir, também, outras imagens que ampliam novas atmosferas existenciais, onde nada se via, nada se sentia, é possível criar e romper as formas imagéticas.

\title{
Réquiem para um igarapé da Amazônia ${ }^{5}$
}

Tenho saudade. Uma saudade que já não cabe dentro de mim, porém não é apenas esta que movimenta as palavras, penso sobre ele, nosso pequeno igarapé Altamira, as veias que nutriam um recorte da Amazônia, do grandioso Xingu.

\begin{abstract}
Altamira, a princesa louçã da transamazônica, banhada pelo majestoso rio Xingu que (re)corta e adentra a mata formando um excelso relevo e mais parece um labirinto de águas profundas e serenas, alcançando um tom de verde tão verdejante que chega a se misturar com o verde da floresta, em uma harmoniosa composição de aquarelas que para mim mais parece um rio-floresta (COSTA; SILVA; BRITO, 2017, p. 2).
\end{abstract}

Recordo-me dos meus antepassados indígenas, os quais passavam horas banhando e brincando nas misteriosas águas esverdeadas do igarapé Altamira, hora sob o sol do verão Amazônico, hora sob a chuva que se misturava com as lembranças. Arrebatamento jubiloso que jamais era interrompido.

\footnotetext{
${ }^{5}$ Todas as frases que estiverem no decorrer do texto destacada em itálico são, também, de moradores que aceitaram conversar e contar um pouco sobre suas histórias, sentimentos, memórias e vivências com o igarapé Altamira e o ambiente (Açaizal e Tufi), as quais criaram outras narrativas para este trabalho.
} 
SILVA, Carlos Augusto Silva e; BRITO, Maria dos Remédios de. Quando um biólogo é inundado por outras biologias, outras educações.

Notícias e mais notícias percorreram: rasgaram a Amazônia. Alguns chamavam de doença, outros de transamazônica. O corte foi profundo e rompeu tudo que estava à frente. Até que avistaram uma altamira. Descobriram o vale, aquele buraco já habitado por Kuruayas, Jurunas, Xipaias, Araras, e outros esquecidos pela história. Porém vos lembro, sem ao menos saber quem são, no sentido de escrever sobre eles outras histórias. Pois bem, como já é sabido, vieram até as margens do igarapé viajantes, cientistas, catequizadores, todos munidos de tralhas, cada qual tinha a sua.

O tempo passou e com ele vieram mais e mais viajantes, ocupando-se das margens do igarapé Altamira. A família do biólogo construiu nele sua morada, crianças ainda brincavam em suas águas. "Abrigo de desabrigados". Era o que diziam. Mas quando! Contavam que estavam poluindo suas águas, todavia ali ele estava, forte como nunca, talvez modificado. Mas quem não muda? Qual igarapé deixaria de sorrir ao proporcionar maneiras outras de se habitar? Qual igarapé deixaria de rir ao ver uma criança de suas águas nascerem? Eram vidas que se misturavam com suas águas sujas, vívidas, periféricas; rejeitadas como o lixo que adornava suas águas.

Esse igarapé era traquina, íntimo dos moradores. De tempos em tempos ele entrava nas casas que ali estavam. Era uma visita programada, geralmente nos meses de dezembro a abril. Lá ele jazia, tomando café com a tia Preta, almoçando com a vó Delfina, brincando com o primo Pedrinho. Às vezes era necessário deixá-lo mais à vontade dentro de casa, sendo assim, muitos dos moradores saíam de suas casas, levando os pertences que podiam, mas logo retornavam. A amizade acontecia, moradores se empenhavam para ajudar o outro, assim como também eram ajudados.

Muitos perguntavam: "como aguentam?" Busquem um lugar mais "adequado" ou “civilizado" para morar. Palermice! Entre palafitas, pontes de madeira, rejeitos e águas sujas, criavam-se modos de existência, naquelas águas nadavam lembranças de toda uma vida, aliás, de vidas.

Depois de ser esquecido por anos, um dia foi lembrado. Um tal de Belo-Monstro por ele se interessou. Na verdade, a paixão era pelo rio Xingu, mas lá estava o igarapé Altamira, o dedo podre do majestoso e formoso Xingu. Arranque-o! Não presta. E quem mora lá? Arranque-os também e, junto com eles, suas palafitas, pontes de madeira feitas à mão, memórias, afectos, lembranças. Disseram-lhe que tais áreas habitadas de rejeitos seriam revitalizadas e 
SILVA, Carlos Augusto Silva e; BRITO, Maria dos Remédios de. Quando um biólogo é inundado por outras biologias, outras educações.

transformadas em um corredor ecológico. A favela daria lugar a um parque para as famílias civilizadas irem passear, todos juntos: a mamãe, o papai, o filhinho e é claro, o cachorrinho. Áreas nobres que embelezariam a famigerada Altamira.

Ora, revitalizar? Diz ser o "ato de dar a vida" ou "retornar a vida". Vitupério! A vida ali nadava por cada molécula de $\mathrm{H}_{2} \mathrm{O}$; por cada oxigênio inalado pelo nariz de uma criança, umedecido pelo catarro; na música ecoada pelo som da martelada a fim de segurar uma lasca de madeira; na performance das lavadeiras que enrijeciam sua musculatura ao atritar a roupa das madames nas tábuas; no equilíbrio das crianças que corriam nas estreitas pontes que (se) conectavam às palafitas. Eram artistas, dançarinos, equilibristas... ladrões, prostitutas, pobres, favelados, marginais...

Figura 1- Instalação artística realizada próximo ao igarapé Altamira

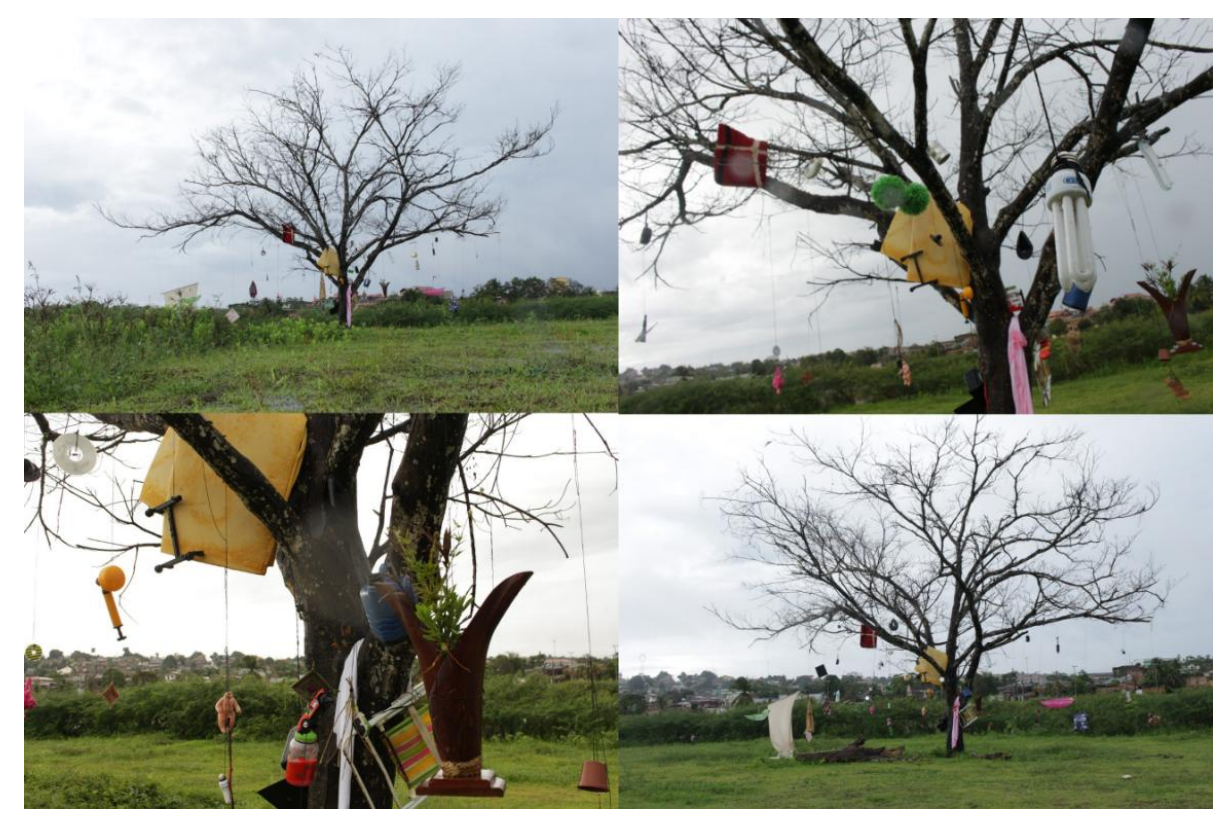

Fonte: SILVA, C. A. Art(e)biologia na/com a natureza. 2018. Dissertação (Mestrado em Educação em Ciências) - Programa de Pós-Graduação em Educação em Ciências e Matemáticas, Instituto de Educação Matemática e Científica, Universidade Federal do Pará, Belém, 2018. p. 110.

Passada meia década e não temos o corredor ecológico, nem o igarapé Altamira. Alguns dizem que ele não aguentou sobre-viver sem seus familiares. Porém, conto-lhes outra história, o igarapé continua vivo. Caminho sobre ele. Todavia, não sou Jesus Cristo. Caminho sob as casas, lixos, colchões, cuscuzeiras, lembranças, afetos, memórias, sorrisos, peixes... Suas águas continuam aqui misturadas ao barro, concreto e grama... Se recombinou e se transformou noutra 
SILVA, Carlos Augusto Silva e; BRITO, Maria dos Remédios de. Quando um biólogo é inundado por outras biologias, outras educações.

coisa; penetrou o solo, navegou pelos barros roxos subterrâneos altamirenses; evaporou, tomou carona com as nuvens. Tudo isso na busca incessante de reencontrar sua família que foi expulsa. Dizem que ele os encontrou, que está lá, conectado a cada corpo, a cada "favelado". Como bons biólogos, averiguem?

Um grupo de biólogos e amigos foram atrás dessas pessoas-águas que viveram décadas naquele lugar, amigos do igarapé Altamira. E assim foi o biólogo, não como bom biólogo, mas como aquele que estava cansado de fazer os mesmos testes e a mesmas experimentações. Ansiava por outras biologias... E quem sabe fazer outro tipo de levantamento, não mais das condições sociais ou testes em águas. Os testes eram outros e as experimentações também: foram coletar um bocado de afetos, memórias, lembranças... (seria isso possível?) Metamorfoseando em Cartógrafo, pois, como se sabe, todo biólogo é meio louco, meio cartógrafo, meio artista.

Figura 2 - Montagem com os moradores entrevistados

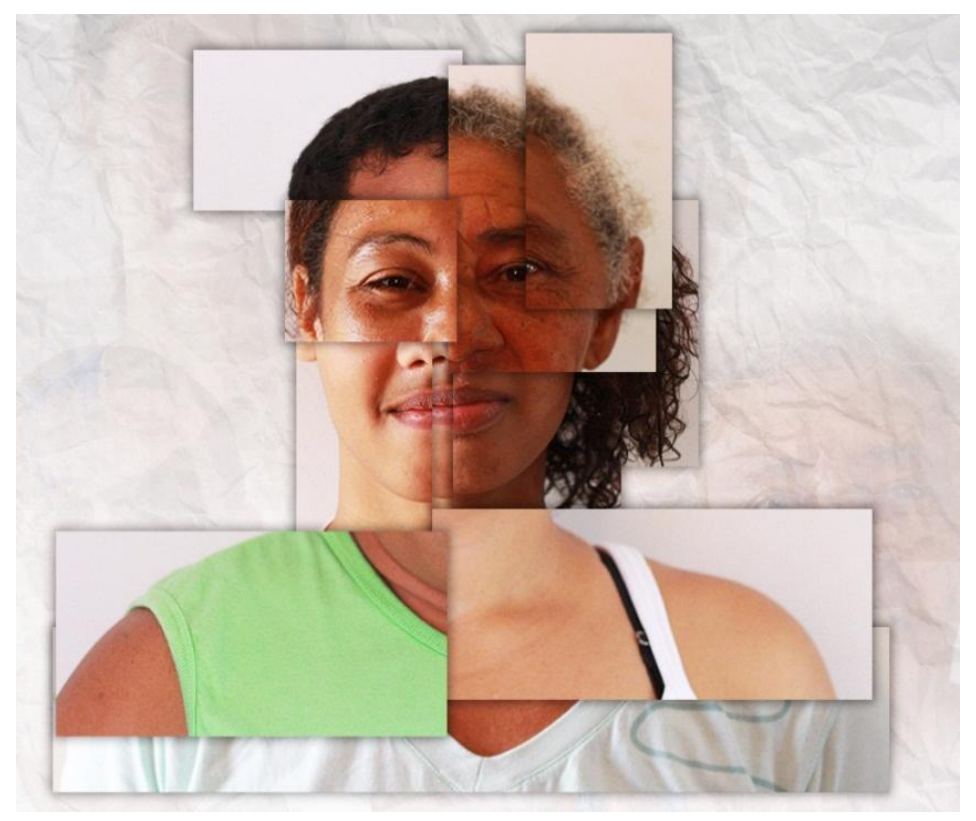

Fonte: SILVA, C. A. Art(e)biologia na/com a natureza. 2018. Dissertação (Mestrado em Educação em Ciências) - Programa de Pós-Graduação em Educação em Ciências e Matemáticas, Instituto de Educação Matemática e Científica, Universidade Federal do Pará, Belém, 2018. p. 111.

Ao conversar com todos aqueles afectos, o biólogo não vi mais pessoas, via-se o próprio igarapé Altamira em concretude, o seu Tufi, os açaís do Açaizal, a mulher que criou o Biólogo. 
SILVA, Carlos Augusto Silva e; BRITO, Maria dos Remédios de. Quando um biólogo é inundado por outras biologias, outras educações.

Figura 3 - Experimentação imagética com as fotografias dos moradores que circundavam o igarapé Altamira

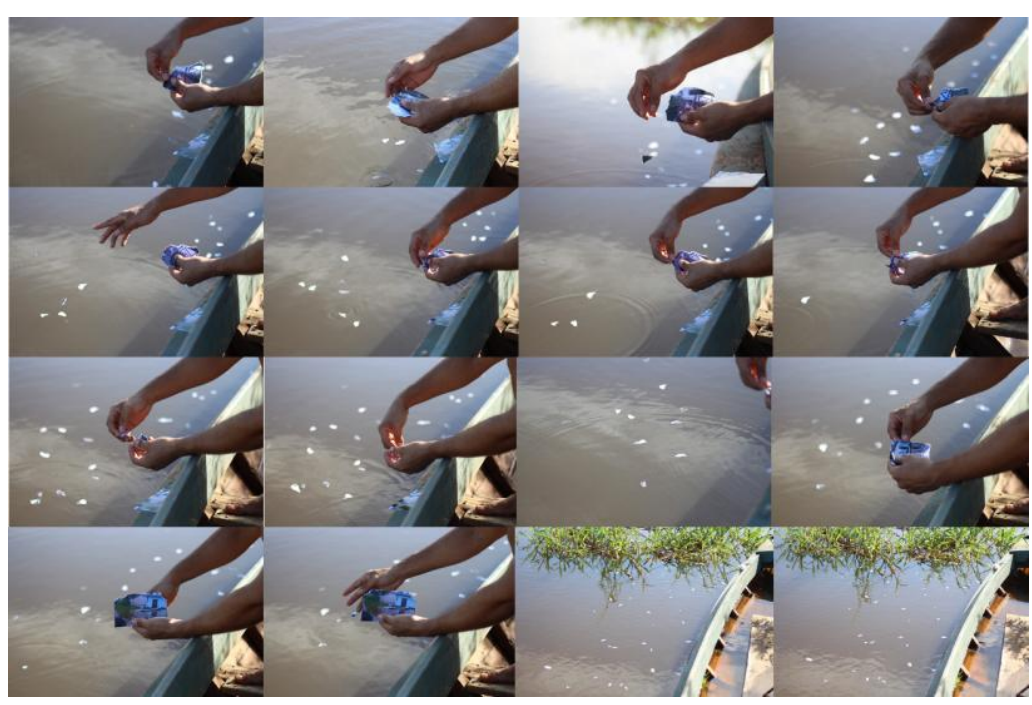

Fonte: SILVA, C. A. Art(e)biologia na/com a natureza. 2018. Dissertação (Mestrado em Educação em Ciências) - Programa de Pós-Graduação em Educação em Ciências e Matemáticas, Instituto de Educação Matemática e Científica, Universidade Federal do Pará, Belém, 2018. p. 112.

\section{Saudade é o nome}

Saudade é o nome. Ele sempre levou o nome da cidade que embelezava: Altamira. Mas já sabemos que seu nome não era apenas Altamira... Sobre ele, calcavam-se diversos apelidos que as pessoas utilizavam para lê-lo. Mas apenas aqueles que estavam lá sabiam como tratá-lo. Palavras que iniciaram este ensaio, mas não deram início a ele, que o encerra, mas não o acaba assim como o igarapé. Palavras que geram vida, aliás, sempre teve vida lá. E a vida acontecia nele, nas suas águas, mesmo quando elas não estavam na forma líquida, a vida acontecia; quando águas baixavam, a crianças corriam para o igarapé seco que ficou debaixo das casas e brincavam, fabulavam-se moradias, pontos dos encontros, tudo acontecia lá... às vezes se brincava de se esconder, ou se fazia casas ali, ou brincava de casais... tinha os primeiros beijos. Se fosse para brigar com alguém da outra rua a "reunião" sempre era debaixo de qualquer casa. Lá poderia ser um lugar não muito legal para se morar, mas todo mundo era bem mais feliz. Foram tempos bons. Todo mundo era bem mais feliz que hoje. Essa lembrança atualiza o presente de Altamira, massacrada pelo capital e a presença para se fazer uma nova terra. 
SILVA, Carlos Augusto Silva e; BRITO, Maria dos Remédios de. Quando um biólogo é inundado por outras biologias, outras educações.

Figura 4 - Placa de publicidade da Norte Energia, empresa responsável pela construção de Belo Monte

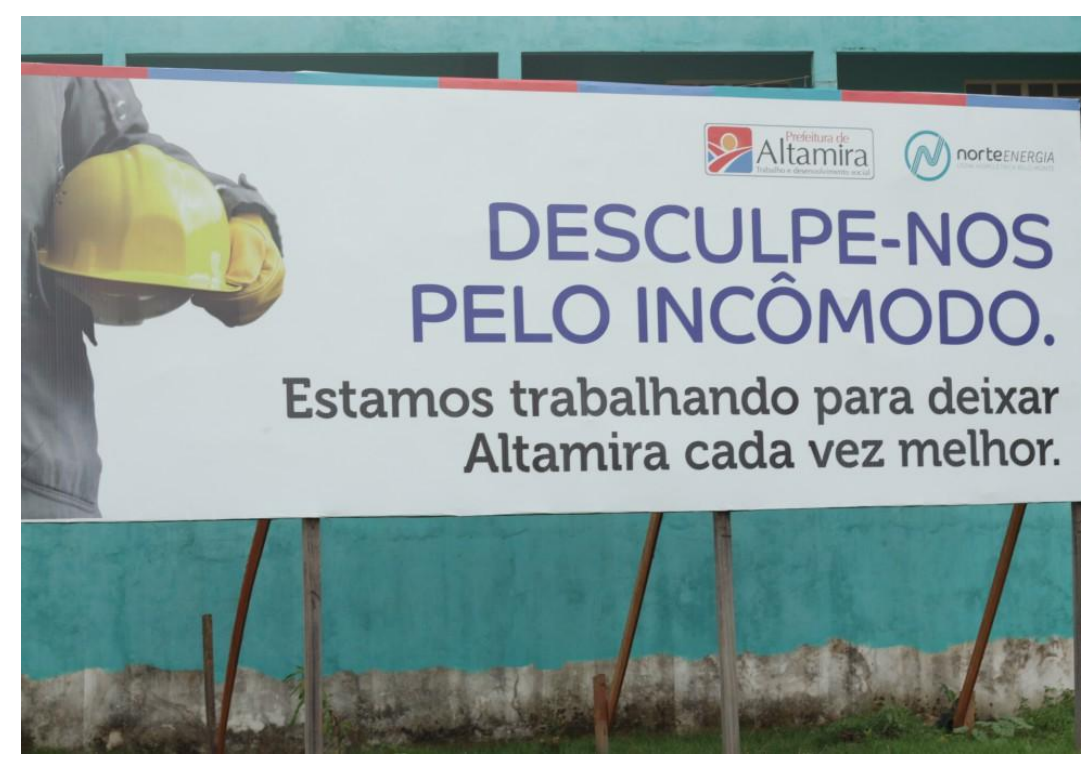

Fonte: SILVA, C. A. Art(e)biologia na/com a natureza. 2018. Dissertação (Mestrado em Educação em Ciências) - Programa de Pós-Graduação em Educação em Ciências e Matemáticas, Instituto de Educação Matemática e Científica, Universidade Federal do Pará, Belém, 2018. p. 108.

Figura 1 - Experimentação com as fotografias dos moradores atingidos pela Usina Hidrelétrica de Belo Monte no parque Altamira

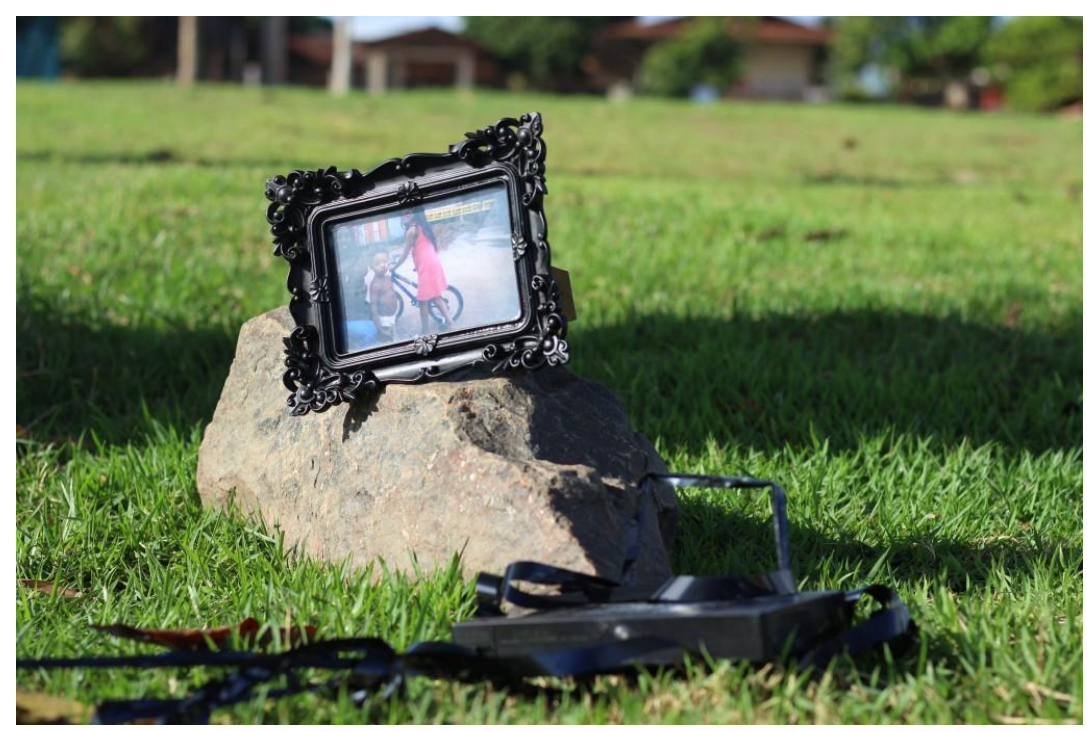

Fonte: SILVA, C. A. Art(e)biologia na/com a natureza. 2018. Dissertação (Mestrado em Educação em Ciências) - Programa de Pós-Graduação em Educação em Ciências e Matemáticas, Instituto de Educação Matemática e Científica, Universidade Federal do Pará, Belém, 2018. p. 113. 
SILVA, Carlos Augusto Silva e; BRITO, Maria dos Remédios de. Quando um biólogo é inundado por outras biologias, outras educações.

\section{Mu-danças}

O igarapé adorava dançar. Tanto que seu verbo preferido era mu-dançar. E assim ele fez, dançou, mudou... Por isso todos sentiram a mudança, ainda mais o biólogo que teve que mudar de casa... Por volta do entardecer ele foi à antiga casa e não tinha mais nada... Só tijolos erguidos, sem telhado, sem porta e janela. Naquela hora chorou, vieram tantas lembranças... Do tempo em que não tinha bloquete... Do tempo da infância mesmo, de chegar em casa sujo de lama e levar uns cacetes por sujar a casa...

Ele chorou, chorou muito com isso... Brincar de bets, queimada, esconde-esconde. Com toda aquela galerinha da rua, tipo uns dez pivetes fazendo bagunça. E depois olhar tudo aquilo e não ver mais nada. Foi bem tenso... Por que já estava chegando as gerações daquelas crianças fazendo o mesmo que ele fez. E cadê elas? Chorou, chorou muito. Nem acesso à ponte ele tinha mais, e hoje em dia a sua casa não existe mais. É certo que não gostava muito da casa que tinha lá, mas quando ele viu que no lugar da casa não tinha mais nada...chorou.

Figura 2 - Experimentação fotográfica com objeto dos moradores no parque Altamira

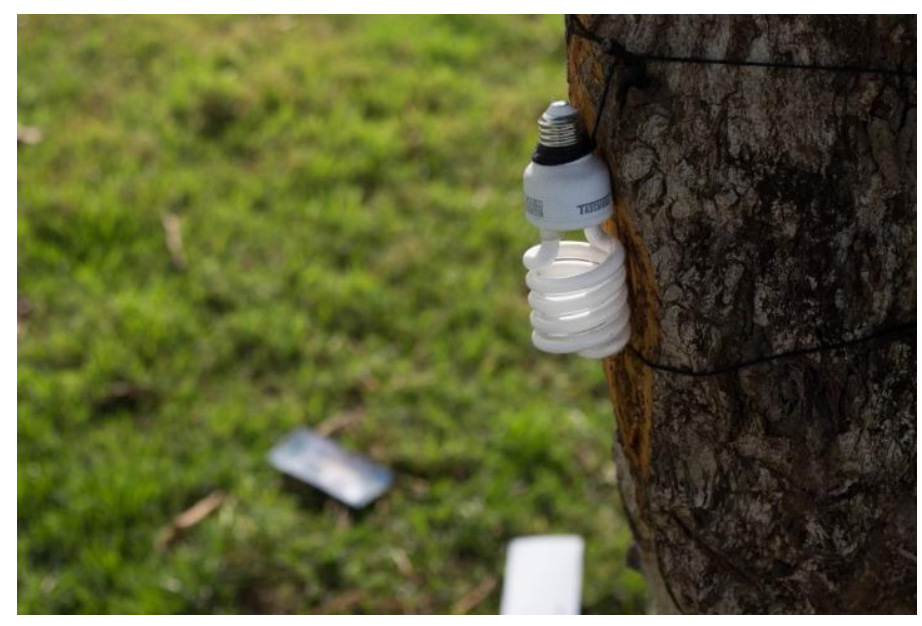

Fonte: SILVA, C. A. Art(e)biologia na/com a natureza. 2018. Dissertação (Mestrado em Educação em Ciências) - Programa de Pós-Graduação em Educação em Ciências e Matemáticas, Instituto de Educação Matemática e Científica, Universidade Federal do Pará, Belém, 2018. p. 114.

Ranciére (2012) propõe argumentar sobre uma trajetória contemporânea das imagens e, com isso, inventa outros destinos para ela. $\mathrm{O}$ autor acredita ser plausível pensar que a imagem tem seu próprio pensamento, sua própria luz... Afeta nossos sentidos: olhar, falar, pensar, 
SILVA, Carlos Augusto Silva e; BRITO, Maria dos Remédios de. Quando um biólogo é inundado por outras biologias, outras educações.

fabricando outros infinitos. São metamorfoses que a imagem provoca: fissurar e fazer transbordar as bordas (Há bordas?). A imagem não para de se reconstruir numa multiplicidade de invenções levando a experiências singulares, que desassossegam e criam destinos para elas próprias. Movem o olhar para novas narrativas do cotidiano, é uma fluidez da imagem, pois toda imagem é um mundo, uma possibilidade de desorganizar as formas estabelecidas para biologia, arte, biólogo e artista, são movimentos de criação.

\section{Morando nas nuvens... Pontes entre os barracos e as vidas}

Figura 3 - Experimentação com as fotografias dos atingidos no parque Altamira

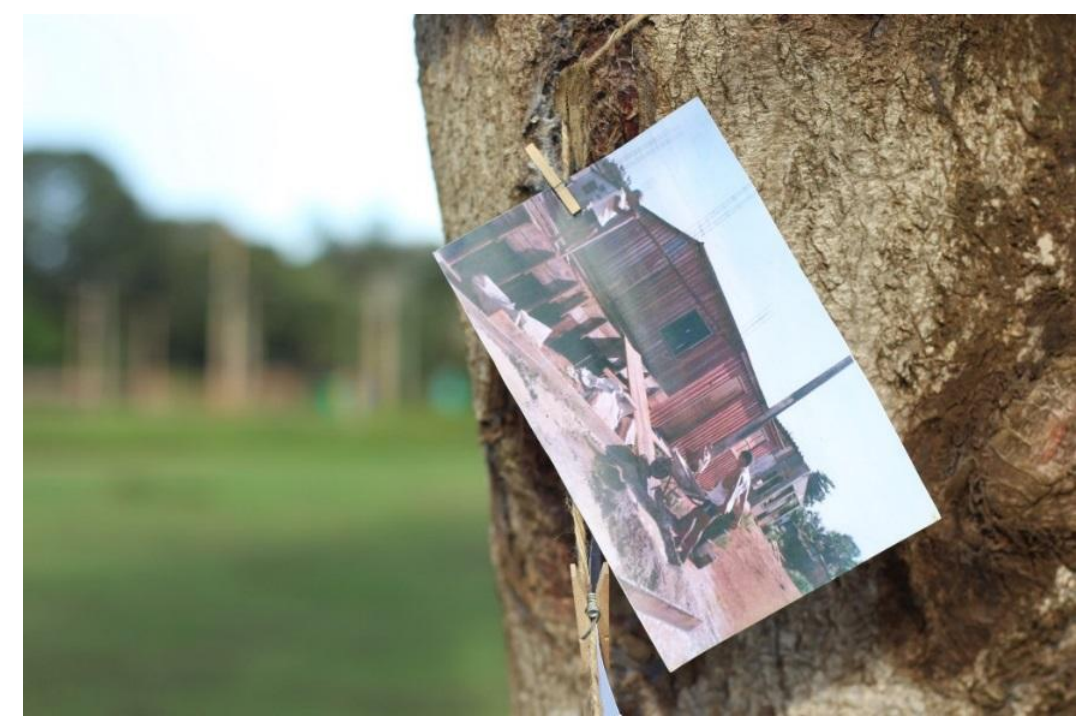

Fonte: SILVA, C. A. Art(e)biologia na/com a natureza. 2018. Dissertação (Mestrado em Educação em Ciências) - Programa de Pós-Graduação em Educação em Ciências e Matemáticas, Instituto de Educação Matemática e Científica, Universidade Federal do Pará, Belém, 2018. p. 115.

As casas eram suspensas, quanto mais alto melhor. Aquela era a casa do biólogo! Até hoje ele usa o termo "lá em casa"... Pois, para ele, a casa ainda existe. Mesmo que seja na memória. Não se pagava ninguém para construir sua casa. Ele se juntava com alguns irmãos e amigos para construir... era o pensamento dele e o dos amigos. Pegava o barraco, construía e ia morar dentro. 
SILVA, Carlos Augusto Silva e; BRITO, Maria dos Remédios de. Quando um biólogo é inundado por outras biologias, outras educações.

Figura 4 - Experimentação com as fotografias dos atingidos no parque Altamira

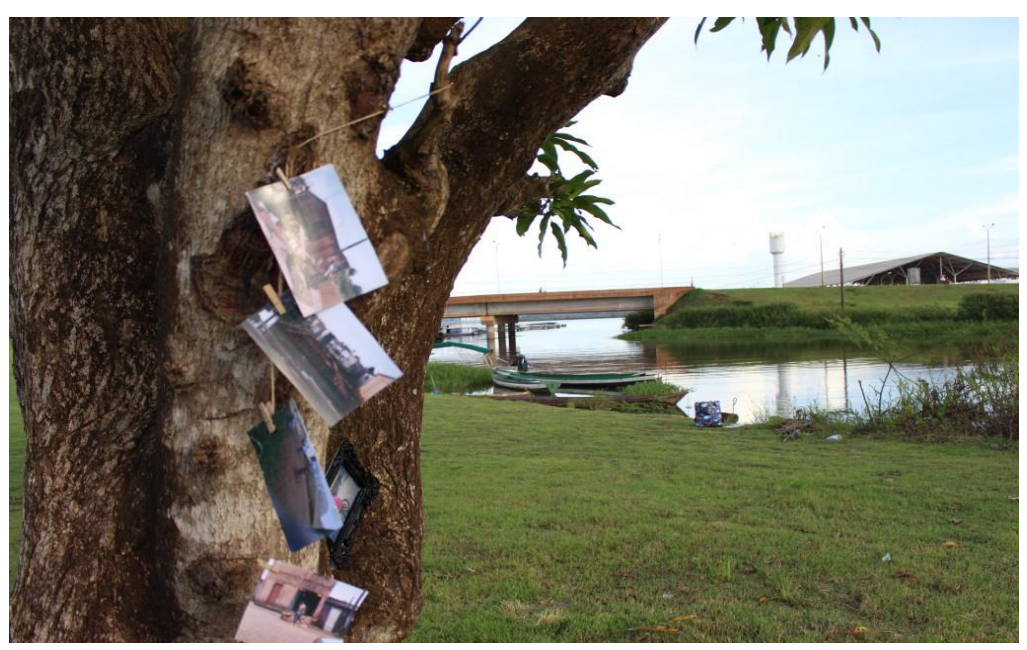

Fonte: SILVA, C. A. Art(e)biologia na/com a natureza. 2018. Dissertação (Mestrado em Educação em Ciências) - Programa de Pós-Graduação em Educação em Ciências e Matemáticas, Instituto de Educação Matemática e Científica, Universidade Federal do Pará, Belém, 2018. p. 115.

Figura 5 - Experimentação com as fotografias dos atingidos no parque Altamira

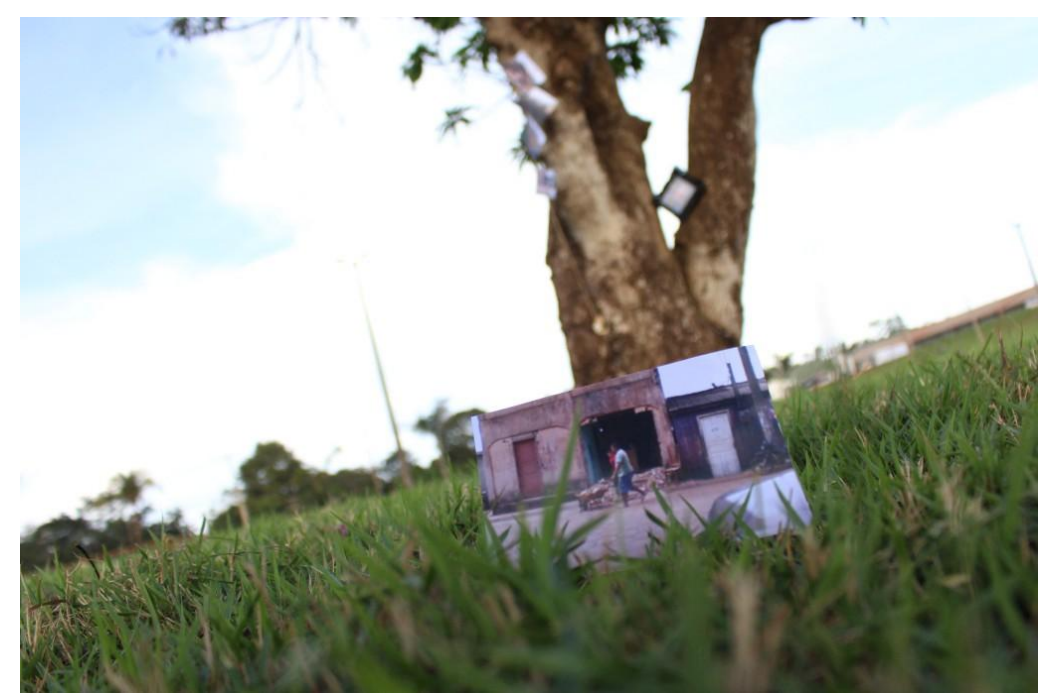

Fonte: SILVA, C. A. Art(e)biologia na/com a natureza. 2018. Dissertação (Mestrado em Educação em Ciências) - Programa de Pós-Graduação em Educação em Ciências e Matemáticas, Instituto de Educação Matemática e Científica, Universidade Federal do Pará, Belém, 2018. p. 116.

Mesmo sendo visto como o bairro mais perigoso da cidade. Não tinha nada disso, todos respeitavam bastante as pessoas que moravam ali. "Ele é meu vizinho, não vou mexer com ele". Não era perigoso como se dizia que era antes. Ele saía na porta da casa e sabia quem ele iria 
SILVA, Carlos Augusto Silva e; BRITO, Maria dos Remédios de. Quando um biólogo é inundado por outras biologias, outras educações.

encontrar. Nem os neguinhos da Fátima mexiam. Se acontecesse algo, eles sempre defendiam... As brigas entre os vizinhos eram coisas de família.

Aonde vão as lembranças que um biólogo viveu/vive, sorriu/sorri, amou/ama, comprou/compra, navegou/navega, semeou/semeia, viu/vê, escutou/escuta, sentiu/sente, gritou/grita, encontrou/encontra, esqueceu/esquece, bebeu/bebe, fumou/fuma, mastigou/mastiga, matou/mata? ... Grudam nas palavras que fazem florescer folhas de vida; imagens que são sementes de poemas. Ele diz: sento-me na beira de um igarapé qualquer, onde tudo é possível, até mesmo pescar as palavras e as imagens que fazem os sentimentos caírem.

Bebedor de palavras, mastigador de folhas, engolidor de lama. O igarapé nasce molhando um povo que bebe palavras, mastiga folhas e engole lama. O igarapé nasce do povo; nasce no povo. Multidões.

\section{A vida de um igarapé (quase) morto}

Viveiro de Castro (CPFL, 2009) relata sobre o encontro dos indígenas que, imbuídos na solidão, adentram a floresta e vivenciam um quase encontro com espíritos. Ora, quase-acontecer é um modo acontecimental, assim, quase morrer desagua num acontecimento. Uma qualidade, um quase somos, quase fomos, quase experimentamos, quase morremos.

$\mathrm{O}$ igarapé quase morreu e isso não significa que ele não morreu, mas que experienciou uma parada, não um término. Morte momentânea. Escapou. Fez nascer da morte uma potência criadora. Atravessou a morte e quase morreu, renasceu e transformou cada molécula da existência numa nova vida alagadiça.

\section{Um igarapé numa poça d’água}

Formas rasas de existir na profundidade das possibilidades. Uma gota d'água é um mundo experimentado. Quem já se perdeu nela? Quem nos mostra essa possibilidade? Abre-se aos encontros, zonas de experimentações heterogêneas, que se potencializaram, mobilizam, abalaram e arrastaram cada um de forma singular, dependendo do encontro e das forças produzidas. E o biólogo e a sua educação foram arrastados ao chão, e nessa violência a desfiguração a partir de um signo foi inevitável, pois todo encontro é um encontro com um signo, "há sempre a violência de um signo que nos força a buscar, que nos rouba a paz” (DELEUZE, 2003, p.14-15). 
SILVA, Carlos Augusto Silva e; BRITO, Maria dos Remédios de. Quando um biólogo é inundado por outras biologias, outras educações.

Figura 6 - Instalação com objetos em árvore no parque Altamira

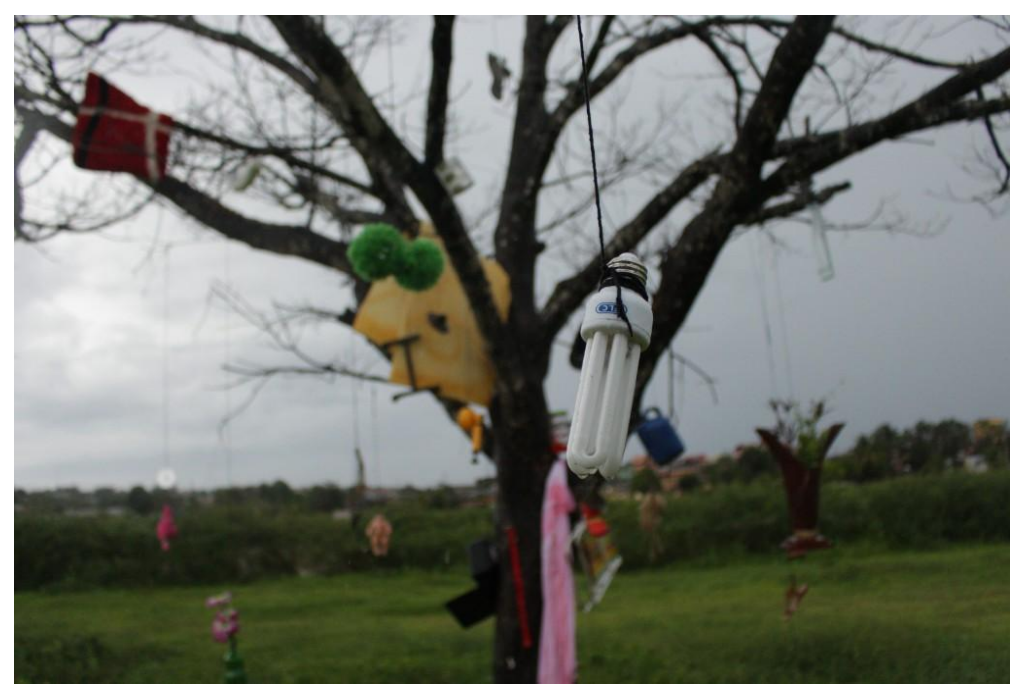

Fonte: SILVA, C. A. Art(e)biologia na/com a natureza. 2018. Dissertação (Mestrado em Educação em Ciências) - Programa de Pós-Graduação em Educação em Ciências e Matemáticas, Instituto de Educação Matemática e Científica, Universidade Federal do Pará, Belém, 2018. p. 117.

Figura 11 - Experimentação com fotografias de moradores no igarapé Altamira.

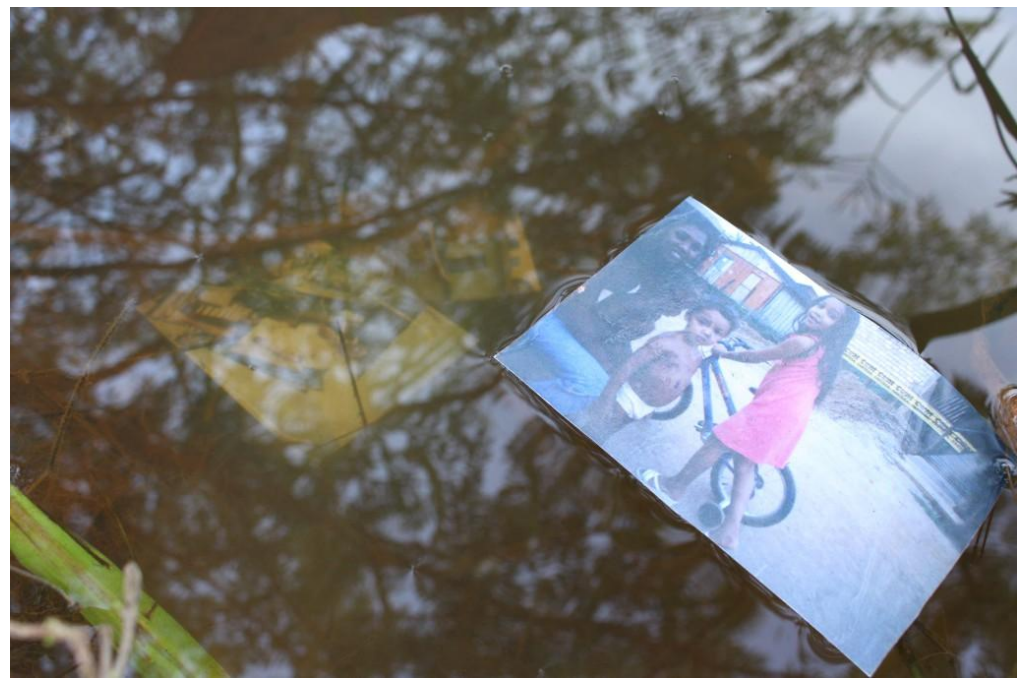

Fonte: SILVA, C. A. Art(e)biologia na/com a natureza. 2018. Dissertação (Mestrado em Educação em Ciências) - Programa de Pós-Graduação em Educação em Ciências e Matemáticas, Instituto de Educação Matemática e Científica, Universidade Federal do Pará, Belém, 2018. p. 118.

\section{Muitas mulheres}

Tia Preta não se diz poetisa, mas nos ensina a re-existir. Cultiva alegrias na sua voz. Carpia a amargura da vida e dava de comer aos pintinhos. Seu ritual é ariar o metal, massacrar o 
SILVA, Carlos Augusto Silva e; BRITO, Maria dos Remédios de. Quando um biólogo é inundado por outras biologias, outras educações.

tecido e cuidar dos filhos, que nem sempre são os dela. Perigosa, dir-se-ia, mata e queima o corpo, dá de comida às águas. Tia preta briga por um pedaço de nuvem que não the foi concedido, se desfaz lavadeira e se recompõe em ameaças; como as folhas que caem e viram outra coisa. Mão ferida, que diz ferir. Tia preta não é só isso.

Arfa os cabelos crespos e tingidos de cinza. Vê na imagem uma possibilidade de se ver diferente. Liga as lanternas para olhar um tempo que não é contínuo, que não é tempo cronológico, é acontecimental. Vem de outros lugares e, assim, lembra que é um peixe fora do aquário, mas desenha nas paredes de vidro outros horizontes, pois ela não é daqui e nem de lá, é simplesmente do caminhar.

Figura 12 - Experimentação com fotografias dos moradores atingidos no igarapé Altamira

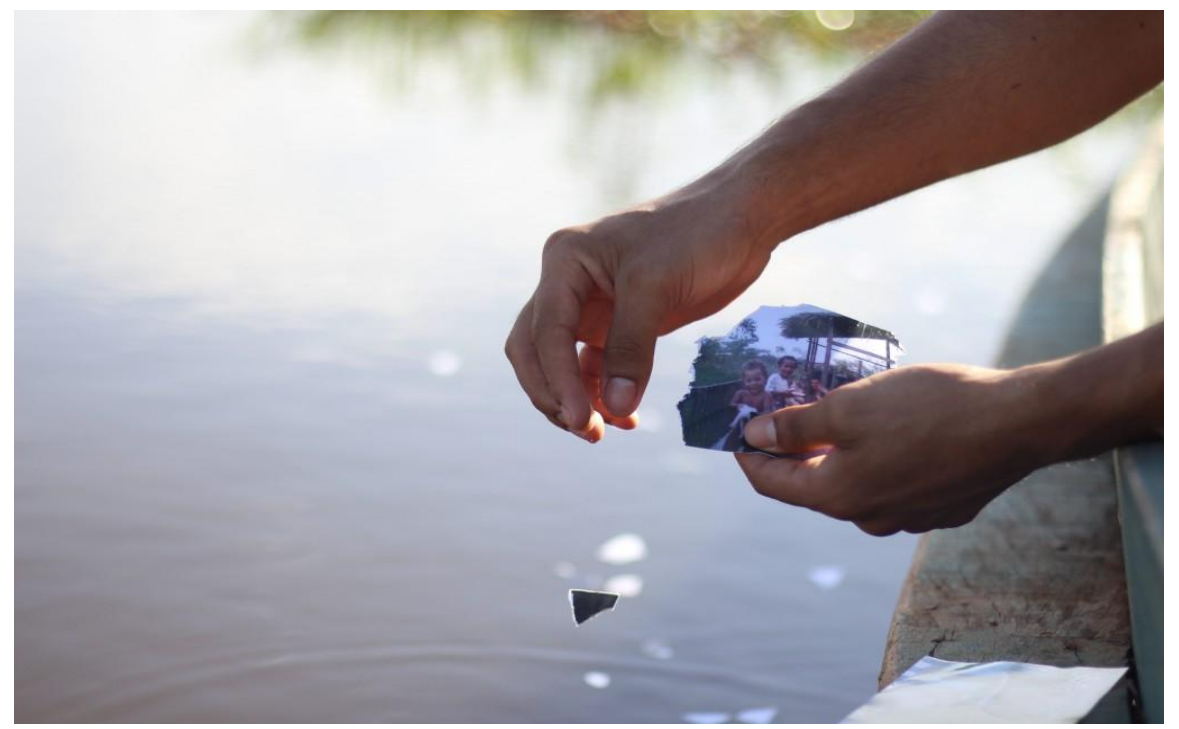

Fonte: SILVA, C. A. Art(e)biologia na/com a natureza. 2018. Dissertação (Mestrado em Educação em Ciências) - Programa de Pós-Graduação em Educação em Ciências e Matemáticas, Instituto de Educação Matemática e Científica, Universidade Federal do Pará, Belém, 2018. p. 119.

\section{Alguns apontamentos finais por uma educação que borram os contornos}

Por meio do diálogo entre a arte e a biologia pode-se criar experimentações que mobilizaram o pensamento para refletir novas formas de conhecer e experimentar os saberes, sem entrar numa questões de merecimentos ou valorização, pois entende-se que a biologia em um sentido mais racional também possui seu valor, e não se nega a historicidade criada a partir dela, logo o que se quis foi inventar outras biologias, várias biologias, por conseguinte um biólogo que se mistura com ela, moradores, igarapés, imagens, entre outros. 
SILVA, Carlos Augusto Silva e; BRITO, Maria dos Remédios de. Quando um biólogo é inundado por outras biologias, outras educações.

Entende-se, aqui, que a educação, a partir da Lei de Diretrizes e Bases da Educação Nacional (BRASIL, 1997), acontece na vida. Diante disso, que educação surgiu a partir das imagens com o igarapé e moradores atingidos pela hidrelétrica de Belo Monte? Que vida é essa que propomos, não apenas estudar como bem fazem os biólogos, mas, sobretudo, experimentar?

Sem dúvidas seria o conforto de uma educação baseada na fragmentação dos saberes, numa formação de professores que esquece a história de vida dos professores, que nos envolvem nessas combinações arcaicas. O que se quer é causar um desconforto na educação, seja ela no ensino de biologia ou na formação de professores de biologia. É fazer alguma coisa estranha atravessar, estranhar o posto, no entanto, estranhar não é suficiente, nunca foi, mas "inventar novas forças ou novas armas" (DELEUZE; PARNET, 1998, p. 5) na e para educação.

Fabular uma educação que dê voz àqueles que foram esquecidos, arrancados das suas casas, dos quais, não se refere apenas aos moradores, mas a todos os seres afetados em prol da produção energética que beneficia, quem?

O que pode essa educação que emergiu de um igarapé sujo, com gosto de lama? Estranha a cultura eurocêntrica dos civilizados, faz reviver o gay da moleta afogado nas águas do rio Xingu e que nos ensinou a rir e inventar novos modos de existência ao desarranjar os códigos pautados pela moral dos bons costumes. A cobra grande, cuja morada é a ilha do capacete, devora Ubiatá. Os Assurini abrem as florestas e presenteia os biólogos com uma ciência menor, mas potente o suficiente para reviver a alma de Macunaíma.

Os ribeirinhos festejam, o Xingu grita, inventam palavras, fazem ciência... A educação é carimbó, minha gente! Tudo isso é educação, minha gente. E agora podemos dançar? Podemos construir um espaço que seja possível criar: arte, biologia e ciência para proliferar invenções no mundo, e, abrir-se na sua multiplicidade que não indica um "ser" para ele, é fazer um, e nesta criação, nunca se tem um sétimo dia onde o mundo está finalizado e adjetivado como "muito bom”. É não se contentar com mundos prontos, com as estações estabelecidas. É saber que a cada dia criam-se mil possibilidades.

A divagação de novos caminhos para se pensar borrar as fronteiras da arte e biologia promove a criação de condições para a invenção de novos sentidos, novos caminhos. Portanto, tremer os contornos é uma possibilidade. Narrar e traduzir as artes e as biologias, experimentando-as, desatando a vida para a potência, para a resistência, para novos caminhos inventivos, pois “criar é resistir efetivamente!” (DELEUZE; PARNET, 1988, p. 90). 
SILVA, Carlos Augusto Silva e; BRITO, Maria dos Remédios de. Quando um biólogo é inundado por outras biologias, outras educações.

Este ensaio não se encerra aqui, nem a trama proposta a ele. São ideias que queimam e se transformam em cinzas, que dão asas às outras biologias e biólogos. Faz florescer um biólogo que é: cartógrafo, tufi, hidrelétrica, Altamira, imagem, processo, corpo, belo monte, baixão, igarapé, moradores... muitos.

Figura 7 - Experimentação com fotografias de moradores atingidos no parque Altamira
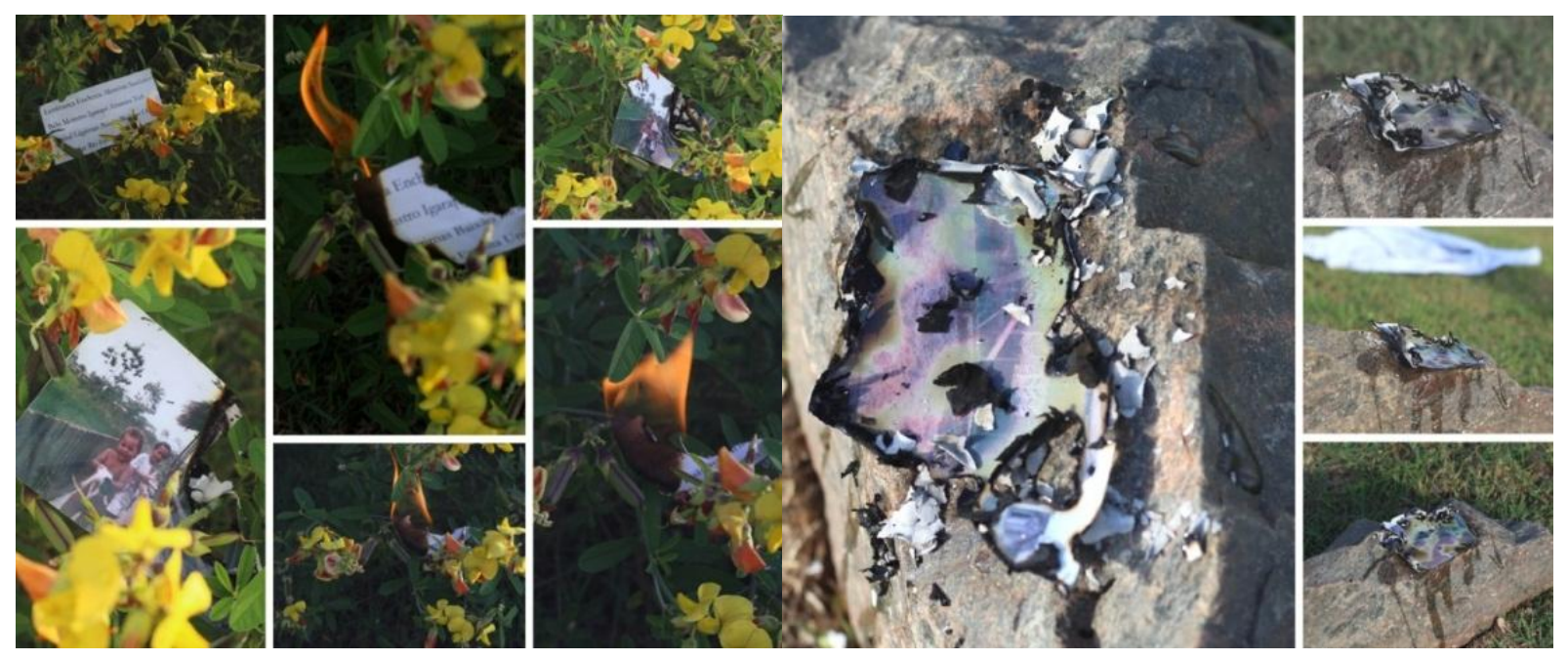

Fonte: SILVA, C. A. Art(e)biologia na/com a natureza. 2018. Dissertação (Mestrado em Educação em Ciências) - Programa de Pós-Graduação em Educação em Ciências e Matemáticas, Instituto de Educação Matemática e Científica, Universidade Federal do Pará, Belém, 2018. p. 119.

\section{Referências}

BRASIL. Lei de diretrizes e bases da educação nacional. Brasília: Conselho de Reitores das Universidades Brasileiras, 1997.

BARROS, M. Menino do mato. Rio de Janeiro, Alfaguara, 2015.

BRITO, M. R.; CHAVES, S. N. ... Cartografia...: uma política de escrita. Revista Polis e Psique, Rio Grande do Sul, v. 7, p. 167-180, 2017.

CPFL. Íntegra: a morte como quase acontecimento: Eduardo Viveiros de Castro. Campinas: Instituto CPFL, 16 out. 2009. Disponível em: http://www.institutocpfl.org.br/2009/10/16/integra-a-morte-comoquase-acontecimento-eduardo-viveiros-de-castro/. Acesso em: 10 abr. 2018.

CORAZZA, S.; SILVA, T. T. Composições. São Paulo: Autêntica, 2003.

COSTA, D. W. S.; SILVA, C. A. S.; BRITO, M. R. Réquiem para ilha do Arapujá. Revista Climacom, Campinas, v. 8, n. 2, p. 1-7, fev. 2017.

DELEUZE, G. Diferença e repetição. Rio de Janeiro: Graal, 2006.

DELEUZE, G. Proust e os signos. Rio de Janeiro: Forense Universitária, 2003. 
SILVA, Carlos Augusto Silva e; BRITO, Maria dos Remédios de. Quando um biólogo é inundado por outras biologias, outras educações.

DELEUZE, G.; GUATTARI, F. O que é a filosofia. São Paulo: Editora 34, 2013.

DELEUZE, G.; PARNET, C. O abecedário de Gilles Deleuze: transcrição integral do vídeo, para fins exclusivamente didáticos. Éditions Montparnasse, Paris, v. 1, n. 1, p. 1-105, jan. 1988.

DELEUZE, G.; PARNET, C. Diálogos. São Paulo: Escuta, 1998.

MACHADO, R. Deleuze, a arte e a filosofia. 2. ed. Rio de Janeiro: Zahar, 2009.

MASNY, D. Cartographies of becoming in education. Rotterdam: SpringerLink, 2013.

PELBART, P. P. Por uma arte de instaurar modos de existência que não existem. Como falar de coisas que não existem. São Paulo: Bienal de São Paulo, 2014.

RAMOS, M. N. C.; BRITO, M. R. As linhas que tecem o aprender e o ensinar em ciências. Ensaio Pesquisa em Educação em Ciências, Belo Horizonte, v. 20, p. 1-20, 2018.

RANCIÉRE, J. O destino das imagens. Rio de Janeiro: Contraponto, 2012. 